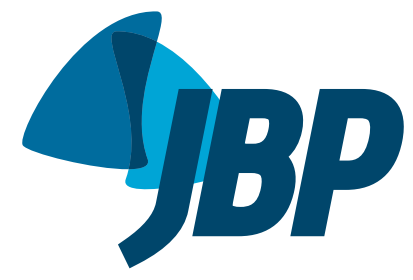

\title{
Administering the Sarcoidosis Health Questionnaire to sarcoidosis patients in Serbia
}

\author{
Violeta Mihailović-Vučinić',2, Branislav Gvozdenović3, Mihailo Stjepanović2, \\ Mira Vuković ${ }^{4}$, Ljiljana Marković-Denićs , Aleksandar Milovanović6, \\ Jelica Videnović-Ivanov², Vladimir Žugić' ${ }^{1,2}$, Vesna Škodrić-Trifunović ${ }^{1,2}$, \\ Snežana Filipovićz ${ }^{2}$ Maja Omčikus²
}

1. Clinic for Pulmonology, Clinical Center of Serbia, Belgrade, Serbia.

2. School of Medicine, University of Belgrade, Belgrade, Serbia.

3. Pharmacovigilance Department, Pharmaceutical Product Development Serbia - PPD Serbia - Belgrade, Serbia.

4. Education Department of Health Center Valjevo, Valjevo, Serbia.

5. Institute of Epidemiology, School of Medicine, University of Belgrade, Belgrade, Serbia.

6. Dr. Dragomir Karajovic Occupational Health Institute of Serbia, Belgrade, Serbia.

Submitted: 7 April 2015

Accepted: 25 August 2015.

Study carried out at the Clinic for Pulmonology, Clinical Center of Serbia, Belgrade, Serbia.

\begin{abstract}
Objective: The aim of this study was to use a Serbian-language version of the diseasespecific, self-report Sarcoidosis Health Questionnaire (SHQ), which was designed and originally validated in the United States, to assess health status in sarcoidosis patients in Serbia, as well as validating the instrument for use in the country. Methods: This was a cross-sectional study of 346 patients with biopsy-confirmed sarcoidosis. To evaluate the health status of the patients, we used the SHQ, which was translated into Serbian for the purposes of this study. We compared SHQ scores by patient gender and age, as well as by disease duration and treatment. Lower SHQ scores indicate poorer health status. Results: The SHQ scores demonstrated differences in health status among subgroups of the sarcoidosis patients evaluated. Health status was found to be significantly poorer among female patients and older patients, as well as among those with chronic sarcoidosis or extrapulmonary manifestations of the disease. Monotherapy with methotrexate was found to be associated with better health status than was monotherapy with prednisone or combination therapy with prednisone and methotrexate. Conclusions: The SHQ is a reliable, disease-specific, self-report instrument. Although originally designed for use in the United States, the SHO could be a useful tool for the assessment of health status in various non-English-speaking populations of sarcoidosis patients.
\end{abstract}

Keywords: Sarcoidosis; Health status; Validation studies; Questionnaires; Self report; Serbia.

\section{INTRODUCTION}

Sarcoidosis is a multisystem, multiorgan disease of unknown etiology and unpredictable course. It is characterized by noncaseating granulomas that can involve any organ system and can affect persons of all races and ages. ${ }^{(1)}$

Albeit a disease with a low mortality rate, sarcoidosis can become a chronic malady in which patients develop various physical and mental disabilities. ${ }^{(1-3)}$ The majority of sarcoidosis patients experience spontaneous disease remission within 2-5 years of diagnosis. ${ }^{(4)}$ However, $10-30 \%$ of sarcoidosis patients develop chronic symptoms or progressive disease that can affect physical functioning and emotional well-being. ${ }^{(4-7)}$

Previous studies in sarcoidosis have focused on the pulmonary manifestations of the disease, as assessed by chest imaging and pulmonary function testing during the evolution of the disease. ${ }^{(8-10)}$ These clinical variables do not always predict long-term outcomes. For the individual patient, chest X-rays and spirometry correlate poorly with perceived quality of life. ${ }^{(11)}$ Reports describing health status and quality of life in sarcoidosis are limited to a few cross-sectional studies conducted in northern Europe or in the United States, ${ }^{(2,5,12-17)}$ in which a variety of generic and respiratory-specific questionnaires have been used. . $^{(2,5,18-23)}$ Our group previously reported results from the use of generic and respiratory-specific instruments for quantifying health status and quality of life in a cross-sectional study of sarcoidosis patients in Serbia. ${ }^{(24,25)}$

Five large-scale studies conducted in Europe reported impaired health status and quality of life in patients with sarcoidosis, in whom physical, emotional, and even social functioning were found to be limited, as they have been in other studies. ${ }^{(2,12-19)}$ In the largest study of its kind conducted in the United States, ${ }^{(26)}$ health status was assessed in 120 sarcoidosis patients with a variety of instruments, including the Medical Outcomes Study 36-item Short-Form Health Survey, the Saint George's Respiratory Questionnaire, the Center for Epidemiologic Studies Depression Scale, and the Perceived Stress Scale. ${ }^{(20,26-28)}$

To our knowledge, there have been no studies specifically evaluating health status in sarcoidosis patients in Central or Eastern Europe. Therefore, the primary aim of this study was to evaluate the health status of sarcoidosis patients with the first disease-specific sarcoidosis questionnaire-the self-report Sarcoidosis

Correspondence to:

Violeta Vučinić. Clinic for Pulmonology, Clinical Center of Serbia, Koste Todorovica 26/20, 11000 Beograd, Serbia.

Tel.: 38111 366-3460. E-mail: violetavucinic@gmail.com

Financial support: This study received financial support from the Serbian Ministry of Education and Science (Grant nos. 175046 and 175081; 2011-2014). 
Health Questionnaire (SHQ)-published in 2003 by a group of authors working in the United States. ${ }^{(29)}$ Additional objectives were to assess the health status of sarcoidosis patients according to the treatment regimen and to assess the feasibility of using the $\mathrm{SHQ}$ in non-English-speaking sarcoidosis patients.

\section{METHODS}

\section{Study design and patient sample}

This was a cross-sectional study. The majority of patients recruited to participate in this study were registered with the Serbian Association of Sarcoidosis, which includes 1,562 patients with various clinical forms of sarcoidosis. We enrolled 346 patients with biopsy-confirmed sarcoidosis, diagnosed at the Clinic for Pulmonology of the Clinical Center of Serbia, in the city of Belgrade, Serbia. The patients were examined at regularly scheduled clinical visits, during which they voluntarily completed the SHQ and underwent spirometry. The study was approved by the local research ethics committee, and all of the patients gave written informed consent.

\section{Health status instrument}

The $\mathrm{SHQ}^{(29)}$ is a 29-item, self-report questionnaire with responses ranging from "all of the time" (score of 1 ) to "none of the time" (score of 7). Higher scores indicate better health status. It takes approximately 10 min to complete the SHQ. This instrument measures three health status domains: daily functioning, physical functioning, and emotional functioning.

The original version of the SHQ was kindly provided to the Serbian Association of Sarcoidosis by Dr. Christopher Cox, of Duke University Medical Center. The instrument was officially translated into Serbian and adapted for use in Serbia with the assistance of two native-speaking language experts-one native speaker of Serbian and one native speaker of English-who worked independently on the translation from English to Serbian and the back-translation from Serbian to English, respectively.

\section{Procedures}

Patients completed the SHQ during their regularly scheduled clinical visits, undergoing pulmonary function testing on a spirometer (MasterLab; Jaeger, Würtzburg, Germany), in accordance with the American Thoracic Society/European Respiratory Society guidelines, ${ }^{(30)}$ on the same day. We used the European Respiratory Society criteria for lung function impairment. (31) We measured DLCO using the single-breath method. ${ }^{(32)}$

Using the organ index devised for the "A Case Control Etiology of Sarcoidosis Study", ${ }^{(33,34)}$ we assessed the current extent of organ involvement in our sarcoidosis patients. The diagnosis of sarcoidosis in any organ system was classified as definite, probable, or possible. Positive organ involvement encompassed the criteria for a definite or probable diagnosis, in accordance with the index cited above.

\section{Treatment}

Based on the clinical outcome, the patients were stratified into two groups: acute sarcoidosis (disease duration < 2 years), comprising 137 patients (39.6\% of the sample); and chronic sarcoidosis (disease duration $\geq 2$ years), comprising 209 patients $(60.4 \%$ of the sample). Among the 346 patients, the recommended treatment regimen was monotherapy with prednisone in $246(71.1 \%)$ and monotherapy with methotrexate in $67(19.5 \%)$. In the chronic sarcoidosis patients, methotrexate was used as monotherapy or as a corticosteroid sparing agent (in combination with 5-10 $\mathrm{mg} /$ day of prednisone as maintenance therapy). No treatment was required in 33 patients (9.5\%), 21 $(63.6 \%)$ of whom were acute sarcoidosis patients, the remaining $12(36.4 \%)$ having chronic, asymptomatic sarcoidosis.

\section{Statistical analysis}

To compare SHQ scores with the clinical characteristics of patients, we used two-sample t-tests for variables with two categories and one-way ANOVA for variables with more than two categories. Correlations were calculated by either the Pearson or Spearman method. Independent variables were considered significant at the $p<0.05$ level in the univariate analyses and were assessed as a single block in multivariate regression models. Because SHQ scores are continuous data, we used multiple linear regression analysis in order to evaluate the contribution of risk factors to the total SHQ score or the score for each of its three domains. We used a stepwise model (backward elimination of variables) in which values of $p<0.05$ indicated statistical significance. The variables evaluated in the multiple linear regression analysis included age (decade of life), gender, parenchymal lung disease on chest $X$-ray, the course of the disease (acute vs. chronic), extrapulmonary disease, specific system involvement (cutaneous, neurological, or cardiac disease), FVC, DLCO, carbon monoxide transfer coefficient, and the treatment regimen (prednisone alone, methotrexate alone, or a combination of the two). Statistical analyses were performed with the Statistical Package for the Social Sciences, version 10.0 (SPSS Inc., Chicago, IL, USA).

\section{RESULTS}

Table 1 summarizes the characteristics of the study patients. At the time of the administration of the SHQ, $33(9.5 \%)$ of the 346 patients were asymptomatic. The remainder reported a variety of health problems, including low energy, fatigue, an undefined feeling of bodily pain, chest tightness, joint pain, and muscle discomfort.

Most-337 (97.4\%) - of the patients had pulmonary involvement, whereas 122 (35.3\%) also had extrapulmonary involvement. Among the 122 patients with extrapulmonary disease, the sarcoidosis affected one organ in $73(59.8 \%)$, two organs in $30(24.6 \%)$, and three or more organs in $19(15.6 \%)$. 
Patients with chronic sarcoidosis had significantly lower scores, indicating poorer health status, for all domains of the SHQ (Table 2). Erythema nodosum was seen in $21(15.3 \%)$ of 137 patients with acute sarcoidosis. Although those patients were expected to show impaired physical functioning, due to polyarthralgia and (in some cases) fever, that was not found to be the case.

Patients were evaluated by decade of life, stratified into seven groups (Table 3). The SHQ scores differed significantly among the age groups for the daily functioning domain (ANOVA $F=3.85$; $p<0.001$ ) and for the physical functioning domain (ANOVA $F=$ 4.49; $p<0.001$ ), as did the total SHQ score (ANOVA $F=4.59 ; p<0.001$ ), although no such difference was found for the emotional functioning domain. The

Table 1. Demographic and clinical characteristics of the patients. ${ }^{a}$

\begin{tabular}{|c|c|}
\hline Characteristic & $N=346$ \\
\hline Age (years), mean \pm SD & $46.03 \pm 10.8$ \\
\hline \multicolumn{2}{|l|}{ Gender } \\
\hline Female & $257(74.3)$ \\
\hline Male & $89(25.7)$ \\
\hline \multicolumn{2}{|l|}{ Ethnicity } \\
\hline White & $346(100.0)$ \\
\hline Symptomatic patients & $313(90.5)$ \\
\hline \multicolumn{2}{|l|}{ Stage of the lung disease } \\
\hline 0 or 1 (no parenchymal lesions) & $233(67.3)$ \\
\hline 2-4 (with parenchymal lesions) & $113(32.7)$ \\
\hline Pulmonary sarcoidosis & $337(97.4)$ \\
\hline Extrapulmonary sarcoidosis & $122(35.3)$ \\
\hline $\begin{array}{l}\text { Number of organ systems involved, } \\
\text { mean (range) }\end{array}$ & $3(1-5)$ \\
\hline \multicolumn{2}{|l|}{ Extrapulmonary organ systems involved } \\
\hline Eye & $68(19.7)$ \\
\hline Skin & $50(14.5)$ \\
\hline Heart & $23(6.7)$ \\
\hline Nervous system (neurosarcoidosis) & $22(6.4)$ \\
\hline Liver & $16(4.6)$ \\
\hline Spleen & $12(3.5)$ \\
\hline Bone & $11(3.6)$ \\
\hline Bone marrow & $1(0.3)$ \\
\hline \multicolumn{2}{|l|}{ Course of the sarcoidosis } \\
\hline Acute & $137(39.6)$ \\
\hline Chronic & $209(60.4)$ \\
\hline \multicolumn{2}{|l|}{ Lung function } \\
\hline Restrictive lung disease (FVC $<80 \%$ ) & $244(70.5)$ \\
\hline $\begin{array}{l}\text { Obstructive lung disease } \\
\left(\mathrm{FEV}_{1} / \mathrm{FVC} \text { ratio }<70 \%\right)\end{array}$ & $10(2.9)$ \\
\hline Normal & $92(26.6)$ \\
\hline \multicolumn{2}{|l|}{ Treatment } \\
\hline None & $33(9.5)$ \\
\hline Prednisone only & $246(71.1)$ \\
\hline Methotrexate only & $21(6.1)$ \\
\hline Methotrexate plus prednisone & $46(13.3)$ \\
\hline
\end{tabular}

avalues expressed as $\mathrm{n}(\%)$, except where otherwise indicated.
114 patients in the 41 - to 50 -year age group had the lowest total SHQ scores, as well as the lowest scores for the daily functioning and physical functioning domains, whereas the 122 patients between 51 and 70 years of age had the lowest scores for the emotional functioning domain. There were only 3 patients over 70 years of age (Table 3 ).

Significant differences were found between the patients with parenchymal lung disease (i.e., those in sarcoidosis stages 2-4) and those without (those in stage 0 or 1 ), in terms of the scores for the SHQ domains daily functioning and physical functioning, as well as total SHQ scores, all of which were lower in the former group (Table 2). Patients in whom the sarcoidosis affected three or more organs had the lowest mean total SHQ score $(3.82 \pm 0.94)$, as well as the lowest mean scores for the domains daily functioning (3.72 \pm 0.91$)$, physical functioning (4.00 \pm 0.98$)$, and emotional functioning $(3.74 \pm 0.95)$. Only the total SHQ score differed significantly between the groups stratified by location/organ involvement. The 50 patients with chronic cutaneous sarcoidosis had significantly lower scores for the daily functioning domain (ANOVA $\mathrm{F}=1.353, \mathrm{p}=0.05$ ). Likewise, the 23 patients with cardiac sarcoidosis had significantly lower scores for the physical functioning domain (ANOVA F $=1.523, \mathrm{p}$ $=0.041$ ), and the 23 patients with neurosarcoidosis had significantly lower total SHQ scores (ANOVA F = 1.912, $p=0.05$ ). However, we found no significant differences among those groups in terms of the scores for the emotional functioning domain.

The scores for the SHQ domains daily functioning and physical functioning were significantly lower among the 122 patients with extrapulmonary sarcoidosis than among those with pulmonary involvement only, as were the total SHQ scores ( $p<0.05$ for all). We also found significant differences between the patients with normal lung function and those with restrictive lung disease (FVC $<80 \%$ ), in terms of the scores for the daily functioning domain (ANOVA $F=1.42 ; p=$ 0.019 ) and the physical functioning domain (ANOVA $F=1.47 ; p=0.012)$, as well as the total SHQ score (ANOVA $F=1.41 ; p=0.023$ ), although we found no such difference in terms of the scores for the emotional functioning domain.

At evaluation, $246(71.1 \%)$ of the 346 patients were under treatment with prednisone only; $21(6.1 \%)$ were under treatment with methotrexate only; 46 $(13.3 \%)$ were under treatment with the combination of methotrexate and low-dose prednisone; and 33 $(9.5 \%)$ were not receiving any pharmacological treatment. The patients receiving monotherapy with prednisone had significantly higher SHQ scores for all domains than did those receiving monotherapy with methotrexate or combination therapy with methotrexate plus prednisone ( $p<0.05$ for all). The 33 untreated patients had higher SHQ scores than did those receiving pharmacological treatment, the differences being statistically significant for all SHQ domains (Table 4). The patients treated with prednisone 
Table 2. Clinical characteristics of sarcoidosis and Sarcoidosis Health Questionnaire scores. ${ }^{\text {a }}$

\begin{tabular}{|c|c|c|c|c|c|}
\hline \multirow[t]{3}{*}{ Characteristic of sarcoidosis } & \multirow[t]{3}{*}{$\mathbf{n}$} & \multicolumn{4}{|c|}{ Sarcoidosis Health Questionnaire scores } \\
\hline & & \multirow[b]{2}{*}{ Daily functioning } & \multicolumn{2}{|l|}{ Domains } & \multirow[t]{2}{*}{ Total } \\
\hline & & & $\begin{array}{l}\text { Physical } \\
\text { functioning }\end{array}$ & $\begin{array}{c}\text { Emotional } \\
\text { functioning }\end{array}$ & \\
\hline \multicolumn{6}{|l|}{ Course } \\
\hline Acute & 137 & $4.80(0.87)$ & $5.00(0.95)$ & $4.35(0.76)$ & $4.72(0.72)$ \\
\hline \multirow[t]{2}{*}{ Chronic } & 209 & $4.16(0.86)$ & $4.43(1.07)$ & $4.13(0.72)$ & $4.24(0.75)$ \\
\hline & & $<0.001$ & $<0.001$ & $<0.05$ & $<0.001$ \\
\hline \multicolumn{6}{|l|}{ Location } \\
\hline Extrapulmonary & 122 & $4.14(0.89)$ & $4.45(1.09)$ & $4.12(0.77)$ & $4.24(0.77)$ \\
\hline \multirow[t]{2}{*}{ Exclusively pulmonary } & 244 & $4.58(0.90)$ & $4.77(1.02)$ & $4.26(0.79)$ & $4.53(0.76)$ \\
\hline & & $<0.001$ & $<0.05$ & $>0.05$ & $<0.001$ \\
\hline \multicolumn{6}{|l|}{ Stage of the lung disease } \\
\hline 0 or 1 (no parenchymal lesions) & 233 & $4.52(0.93)$ & $4.78(1.03)$ & $4.25(0.81)$ & $4.52(0.78)$ \\
\hline 2-4 (with parenchymal lesions) & 113 & $4.19(0.85)$ & $4.40(1.08)$ & $4.14(0.75)$ & $4.24(0.74)$ \\
\hline$p^{*}$ & & $<0.05$ & $<0.05$ & $>0.05$ & $<0.05$ \\
\hline
\end{tabular}

avalues expressed as mean $\pm \mathrm{SD}$. *t-test.

Table 3. Age of sarcoidosis patients (by decade of life) and Sarcoidosis Health Questionnaire scores. ${ }^{a}$

\begin{tabular}{|c|c|c|c|c|c|c|c|}
\hline \multirow{2}{*}{$\begin{array}{c}\text { SHQ } \\
\text { scores }\end{array}$} & \multicolumn{7}{|c|}{ Decade of life (years) } \\
\hline & $\begin{array}{c}11-20 \\
(n=2)\end{array}$ & $\begin{array}{c}21-30 \\
(n=24)\end{array}$ & $\begin{array}{c}31-40 \\
(n=81)\end{array}$ & $\begin{array}{c}41-50 \\
(n=114)\end{array}$ & $\begin{array}{c}51-60 \\
(n=95)\end{array}$ & $\begin{array}{c}61-70 \\
(n=27)\end{array}$ & $\begin{array}{c}71-80 \\
(n=3)\end{array}$ \\
\hline DF domain & $4.69(1.09)$ & $4.84(0.84)$ & $4.73(1.04)$ & $4.20(0.84)$ & $4.32(0.90)$ & $4.30(0.69)$ & $4.41(0.31)$ \\
\hline PF domain & $5.66(0.47)$ & $5.11(0.69)$ & $5.02(1.04)$ & $4.42(1.10)$ & $4.49(1.05)$ & $4.61(0.92)$ & $5.44(0.42)$ \\
\hline EF domain & $4.95(1.48)$ & $4.54(0.75)$ & $4.34(0.92)$ & $4.14(0.73)$ & $4.12(0.77)$ & $4.12(0.65)$ & $4.36(0.21)$ \\
\hline Total & $5.10(1.01)$ & $4.83(0.60)$ & $4.70(0.85)$ & $4.25(0.76)$ & $4.31(0.75)$ & $4.34(0.59)$ & $4.74(0.17)$ \\
\hline
\end{tabular}

SHQ: Sarcoidosis Health Questionnaire; DF: daily functioning; PF: physical functioning; and EF: emotional functioning. avalues expressed as mean \pm SD.

only were divided into those with acute sarcoidosis $(n=$ $104)$ and those with chronic sarcoidosis $(n=142)$. The prescribed doses of prednisone were higher for those with acute disease than for those with chronic disease (20-30 mg/day vs. 5-10 mg/day). The mean daily functioning domain score, physical functioning domain score, and total SHQ score were significantly lower among the patients with chronic sarcoidosis than among those with acute sarcoidosis $(p<0.05)$, although the mean emotional functioning domain score was not. Among the patients treated with prednisone, the mean emotional functioning domain score was higher in the acute sarcoidosis group (higher daily doses) than in the chronic sarcoidosis group (lower daily doses), as can be seen in Table 5 .

In the multivariate analysis, chronic disease and cardiac disease were both found to be independent predictors of lower scores for the SHQ domain daily functioning. Chronic disease, combination therapy (prednisone plus methotrexate), and neurosarcoidosis were found to be independent predictors of lower physical functioning domain scores, whereas female gender and prednisone monotherapy were found to be independent predictors of lower emotional functioning domain scores. As shown in Table 6, female gender, chronic disease, combination therapy, and neurosarcoidosis were significantly associated with lower total SHQ scores.

\section{DISCUSSION}

In the present study, we have assessed the health status of sarcoidosis patients using the first sarcoidosis-specific health status questionnaire (the SHQ). We found that, among the 346 sarcoidosis patients evaluated, health status was significantly impaired in all three SHQ domains (daily functioning, physical functioning, and emotional functioning).

The overall health status (total SHQ score) was significantly lower in the female patients in our sample. In addition, we noted that the proportion of patients with chronic disease was significantly higher among the female patients (77.5\%) than among the male patients $(68.8 \%)$, which could explain the significantly lower SHQ scores among the female patients. In the largest sarcoidosis health status study conducted in the United States, $87(78.4 \%)$ of the 111 sarcoidosis patients evaluated were female, although the authors did not report poorer health status for the female patients. (26) In the original SHQ validation study, involving 111 sarcoidosis patients, those same authors found no significant difference between the genders in terms of health status. ${ }^{(29)}$ Another recent study conducted in the United States showed significant gender differences for the SHQ physical functioning domain. ${ }^{(35)}$ In the present study, patients in the 41- to 50-year age group had the lowest SHQ scores. Unfortunately, those are often the most economically productive years and overall 
poor health status creates a burden for such patients. Although the mean age of the patients in the original SHQ validation study was approximately 45 years, ${ }^{(29)}$ the authors found no significant age-related difference in SHQ scores in their subsequent sarcoidosis health status study. ${ }^{(26)}$

The significantly lower SHQ scores in our patients with chronic sarcoidosis underscore the importance of patient perception of the burden of chronic sarcoidosis, predominantly in the daily functioning and emotional functioning domains. In the original SHQ validation study, ${ }^{(29)}$ the proportion of patients who characterized their health status as fair-48 (43.2\%)-did not differ significantly from that of those who characterized it as poor-16 (14.4\%). However, in the subsequent study conducted by the same authors, there was a statistically significant difference between the symptomatic patients and asymptomatic patients, in terms of the mean total SHQ score. ${ }^{(26)}$ In the present study, we found significant differences in the SHQ scores between the patients with acute sarcoidosis and those with chronic sarcoidosis, the former having significantly higher scores for all SHQ domains.

We also found that the scores for the daily functioning, physical functioning, and emotional functioning domains of the SHQ were inversely associated with the number of organ systems affected by sarcoidosis. Likewise, in the sarcoidosis health status study conducted in the United States, a higher the number of affected organs translated to lower SHQ scores. ${ }^{(26)}$

Because studies conducted in Europe have not utilized the SHQ, the results of those studies cannot be compared with those of the present study. However, comparing our results with those of the sarcoidosis health status study conducted in the United States, in which the SHQ was also employed, we noticed differences between the two patient samples. In the sample evaluated in the latter study, $80 \%$ of the patients were African American, (26) which often correlates with clinical phenotypes that are associated with more severe disease, a more aggressive course, and a worse prognosis. ${ }^{(36)}$

One limitation of our study is that we evaluated health status only with a disease-specific instrument (the SHQ) and did not compare those findings with those that might have been obtained with instruments that are more generic or with respiratory-specific questionnaires. However, in a recent study involving a predominantly European population of sarcoidosis patients, the SHQ was shown to correlate well with measures of health-related quality of life and fatigue. ${ }^{(19)}$

In the original $\mathrm{SHQ}$ validation study conducted in the United States, ${ }^{(29)}$ the authors found that prednisone therapy was associated with lower SHQ scores and therefore with poorer health status. However, they were unable to determine the degree of influence that prednisone treatment had on the disease course. The patients enrolled in the present study were diagnosed and treated at a facility where prednisone is the first-line therapy for sarcoidosis. After two or three relapses, prednisone is usually withdrawn and methotrexate is prescribed, either as monotherapy or in combination with low doses of prednisone. The multiple linear regression analysis revealed that the chronic sarcoidosis patients treated with the methotrexate-prednisone combination had significantly lower scores for the SHQ domains physical functioning and emotional functioning, as well as lower total SHQ scores, in comparison with the

Table 4. Comparison of Sarcoidosis Health Questionnaire scores, by treatment regimen. ${ }^{\text {a }}$

\begin{tabular}{|c|c|c|c|c|c|}
\hline \multirow[t]{2}{*}{ Treatment } & \multirow[t]{2}{*}{ n } & \multicolumn{4}{|c|}{ Sarcoidosis Health Questionnaire scores } \\
\hline & & Daily functioning & $\begin{array}{l}\text { Physical } \\
\text { functioning }\end{array}$ & $\begin{array}{l}\text { Emotional } \\
\text { functioning }\end{array}$ & \\
\hline None & 33 & $4.71(0.94)$ & $4.98(1.11)$ & $4.33(0.88)$ & $4.67(0.82)$ \\
\hline Prednisone only & 246 & $4.51(0.93)$ & $4.78(1.01)$ & $4.28(0.79)$ & $4.52(0.76)$ \\
\hline Methotrexate only & 21 & $4.15(0.64)$ & $4.05(0.96)$ & $3.93(0.74)$ & $4.05(0.58)$ \\
\hline Methotrexate plus prednisone & 46 & $3.86(0.68)$ & $4.06(1.04)$ & $3.93(0.66)$ & $3.95(0.67)$ \\
\hline $\mathrm{F}^{*}$ & & 5.49 & 6.11 & 3.27 & 6.68 \\
\hline$p^{*}$ & & $<0.0001$ & $<0.0001$ & $<0.05$ & $<0.0001$ \\
\hline
\end{tabular}

avalues expressed as mean \pm SD. *ANOVA

Table 5. Comparison of Sarcoidosis Health Questionnaire scores among prednisone-treated patients, by sarcoidosis course. ${ }^{\mathrm{a}}$

\begin{tabular}{|c|c|c|c|c|c|}
\hline \multirow{3}{*}{$\begin{array}{l}\text { Course of } \\
\text { sarcoidosis }\end{array}$} & \multirow[t]{3}{*}{$\mathbf{n}$} & \multicolumn{4}{|c|}{ Sarcoidosis Health Questionnaire scores } \\
\hline & & \multicolumn{3}{|c|}{ Domains } & Total \\
\hline & & Daily functioning & Physical functioning & Emotional functioning & \\
\hline Acute $^{b}$ & 104 & $4.79(0.87)$ & $5.00(0.94)$ & $4.37(0.81)$ & $4.71(0.71)$ \\
\hline \multirow[t]{2}{*}{ Chronic $^{c}$} & 142 & $4.27(0.92)$ & $4.59(1.04)$ & $4.21(0.77)$ & $4.36(0.77)$ \\
\hline & & $<0.001$ & 0.001 & $>0.01$ & $<0.001$ \\
\hline
\end{tabular}

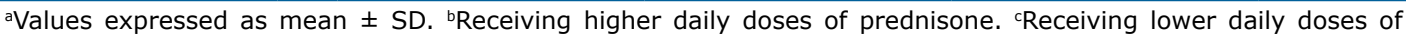
prednisone. *t-test. 
Table 6. Multiple linear regression analyses of various risk factors for lower Sarcoidosis Health Questionnaire scores. ${ }^{a}$

\begin{tabular}{|c|c|c|c|c|}
\hline \multirow[t]{3}{*}{ Variable } & \multicolumn{4}{|c|}{ Multiple linear regression analyses } \\
\hline & \multicolumn{3}{|c|}{ SHQ domain scores } & \multirow{2}{*}{$\begin{array}{c}\text { Total SHQ } \\
\text { score }\end{array}$} \\
\hline & Daily functioning & Physical functioning & Emotional functioning & \\
\hline Gender (male vs. female) & ns & ns & $-0.165(0.003)$ & $-0.138(0.010)$ \\
\hline Course (acute vs. chronic) & $-0.449(0.004)$ & $-0.202(0.000)$ & ns & $-0.216(0.000)$ \\
\hline Therapy (P vs. MTX vs. P+MTX) & ns & $-0.153(0.008)$ & $0.120(0.041)$ & $0.143(0.013)$ \\
\hline Neurosarcoidosis & ns & $0.116(0.036)$ & ns & $0.109(0.046)$ \\
\hline Cardiac disease & $0.345(0.024)$ & ns & ns & ns \\
\hline
\end{tabular}

SHQ: Sarcoidosis Health Questionnaire; P: prednisone; MTX: methotrexate; and ns: not significant. ${ }^{\text {a Statistics }}$ shown as $\beta(p)$.

chronic sarcoidosis patients treated with prednisone alone. In addition, compared with the patients receiving the combination therapy, those receiving monotherapy with methotrexate had significantly better SHQ scores for all domains. That is the outstanding finding of this study. Decisions regarding treatment were based on physician perceptions of the severity of the disease. It is possible, in fact, that the patients treated with methotrexate alone exhibited less severe illness than did those treated with the methotrexate-prednisone combination.

We found the SHQ to be a useful instrument for assessing the health status of sarcoidosis patients in Serbia. The questionnaire was successfully translated into Serbian, and the results obtained were similar to those reported for a population of sarcoidosis patients in the United States. In addition, we have demonstrated significant differences in health status for the sarcoidosis patients who were female, as well as for those with the chronic form of the disease and for those in whom the sarcoidosis affected multiple organ systems. Furthermore, we found that monotherapy with methotrexate was associated with better SHQ scores than was monotherapy with prednisone or combination therapy with methotrexate plus prednisone. The SHQ can be a useful tool for comparing health status in sarcoidosis patient populations of various ethnic and geographic origins.

\section{ACKNOWLEDGMENTS}

We are thankful to Dr. Christopher Cox, of Duke University Medical Center, for providing us with the original SHQ and calculator, as well as granting us permission for its use. We are also grateful to Dr. Elyse Lower, of the University of Cincinnati Department of Internal Medicine, for her assistance and suggestions, both scientific and linguistic, in writing this manuscript.

\section{REFERENCES}

Statement on sarcoidosis. Joint Statement of the American Thoracic Society (ATS), the European Respiratory Society (ERS) and the World Association of Sarcoidosis and Other Granulomatous Disorders (WASOG) adopted by the ATS Board of Directors and by the ERS Executive Committee, February 1999. Am J Respir Crit Care Med. 1999;160(2):736-55.

2. Wirnsberger RM, de Vries J, Breteler MH, van Heck GL, Wouters $E F$, Drent M. Evaluation of quality of life in sarcoidosis patients. Respir Med. 1998;92(5):750-6. http://dx.doi.org/10.1016/S09546111(98)90007-5

3. Chang B, Steimel J, Moller D, Baughman RP, Judson MA, Yeage $\mathrm{H} \mathrm{Jr}$, et al. Depression in Sarcoidosis. Am J Respir Crit Care Med. 2001;163(2):329-34. http://dx.doi.org/10.1164/ajrccm.163.2.2004177

4. Judson MA. Sarcoidosis: clinical presentation, diagnosis, and approach to treatment. Am J Med Sci. 2008;335(1):26-33. http:// dx.doi.org/10.1097/MAJ.0b013e31815d8276

5. Judson MA. An approach to the treatment of pulmonary sarcoidosis with corticosteroids: the six phases of treatment. Chest. 1999;115(4):1158-65. http://dx.doi.org/10.1378/chest.115.4.1158

6. Chang JA, Curtis JR, Patrick DL, Raghu G. Assessment of healthrelated quality of life in patients with interstitial lung disease. Chest. 1999;116(5):1175-82. http://dx.doi.org/10.1378/chest.116.5.1175

7. De Vries J, Wirnsberger R. Fatigue, quality of life and health status in sarcoidosis. In: Drent M, Costabel U, editors. Sarcoidosis. European Respiratory Monograph 32. Lausanne: European Respiratory Society; 2005. p. 92-104. http://dx.doi.org/10.1183/1025448x.00032007

8. Loddenkemper R, Kloppenborg A, Schoenfeld N, Grosser H, Costabel U, Clinical findings in 715 patients with newly detected pulmonary sarcoidosis-results of a cooperative study in former West Germany and Switzerland. WATL Study Group. Wissenschaftliche Arbeitsgemeinschaft für die Therapie von Lungenkrankheitan. Sarcoidosis Vasc Diffuse Lung Dis. 1998;15(2):178-82.

9. Hunninghake GW, Gilbert S, Pueringer R, Dayton C, Floerchinge
C, Helmers R, et al. Outcome of the treatment for sarcoidosis. Am J Respir Crit Care Med. 1994;149(4 Pt 1):893-8. http://dx.doi. org/10.1164/ajrccm.149.4.8143052

10. Gibson GJ, Prescott RJ, Muers MF, Middleton WG, Mitchell DN Connolly CK, et al. British Thoracic Society sarcoidosis study: effects of long term corticosteroid treatment. Thorax. 1996;51(3):238-47. http://dx.doi.org/10.1136/thx.51.3.238

11. Pietinalho $A$, Tukiainen $P$, Jaahtela $T$, Persson $T$, Selroos $O$ Finnish Pulmonary Sarcoidosis Study Group. Early treatment of stage II sarcoidosis improves 5-year pulmonary function. Chest. 2002;121(1):24-31. http://dx.doi.org/10.1378/chest.121.1.24

12. De Vries J, Drent M, Van Heck GL, Wouters EF. Quality of life in sarcoidosis: a comparison between members of a patient organisation and a random sample. Sarcoidosis Vasc Diffuse Lung Dis. 1998;15:183-188.

13. Drent $M$, Wimsberger RM, Breteler MH, Kock LM, de Vries J, Wouters EF. Quality of life and depressive symptoms in patients suffering from sarcoidosis. Sarcoidosis Vasc Diffuse Lung Dis. 1998;15(2):59-66.

14. De Vries J, Michielsen H, Van Heck G, Drent M. Measuring fatigue in sarcoidosis: The Fatigue Assessment Scale (FAS). Br J Health Psychol. 2004;9(Pt 3):279-91. http://dx.doi.org/10.1348/1359107041557048

15. Wirnsberger RM, Drent M, Hekelaar N, Breteler $M H$, Drent S Wouters EF, et al. Relationship between respiratory muscle function and quality of life in sarcoidosis. Eur Respir J. 1997;10(7):1450-5. http://dx.doi.org/10.1183/09031936.97.10071450

16. De Vries J, Rothkrantz-Kos S, van Dieijen-Visser MP, Drent M. The relationship between fatigue and clinical parameters in pulmonary sarcoidosis. Sarcoidosis Vasc Diffuse Lung Dis. 2004;21(2):127-36.

17. Drent $M$, Wirnsberger $R$, de Vries J, van Dieijen-Visser MP, Wouters $E F$, Schols AM. Association of fatigue with an acute phase response in sarcoidosis. Eur Respir J. 1999;13(4):718-22. http://dx.doi. org/10.1034/j.1399-3003.1999.13d03.x 
18. Guyatt GJ, Feeny DJ, Patrick DL. Measuring health-related quality of life. Ann Intern Med. 1993;118(8):622-9. http://dx.doi. org/10.7326/0003-4819-118-8-199304150-00009

19. De Boer S, Wilsher ML. Validation of the Sarcoidosis Health Questionnaire in a non-US population. Respirology. 2012;17(3):51924. http://dx.doi.org/10.1111/j.1440-1843.2012.02134.x

20. Antoniou K, Tzanakis N, Tzouvelekis A, Samiou M, Symvoulakis EK, Siafakas NM, et al. Quality of life in patients with active sarcoidosis in Greece. Eur J Intern Med. 2006;17(6):421-6. http://dx.doi. org/10.1016/.jejim.2006.02.024

21. Ware JE Jr, Sherbourne CD. The MOS 36-item short-form health survey (SF-36). I. Conceptual framework and item selection. Med Care. 1992;30(6):473-83. http://dx.doi.org/10.1097/00005650199206000-00002

22. Bowling A. Measuring Disease: A Review of Disease-specific Quality of Life Measurement Scales. Buckingham: Open University Press; 1995.

23. Bergner M, Bobbit RA, Kressel S, Pollard WE, Gilson BS, Morris JR. The sickness impact profile: conceptual foundation and methodology for the development of health status measure. Int J Health Serv. 1976;6(3):393-415. http://dx.doi.org/10.2190/RHE0-GGH4-410WLA17

24. Gvozdenovic BS, Mihailovic-Vucinic V, llic-Dudvarski A, Zugic V, Judson MA. Differences in symptom severity and health status impairment between patients with pulmonary and pulmonary plus extrapulmonary sarcoidosis. Respir Med. 2008;102(11):1636-42. http://dx.doi.org/10.1016/j.rmed.2008.05.001

25. Grozdenovic BS, Mihailovic-Vucinic V, Videnovic J, Zugic V, llicDudvarski A, Filipovic $S$. Quality of life and health status in sarcoidosis patients. In: Hoffmann EC, editor. Health-related quality of life. New York: Nova Science Publishers; 2009. p. 119-32

26. Cox CE, Donohue JF, Brown CD, Kataria YP, Judson MA. Health-related quality of life of persons with sarcoidosis. Chest. 2004;125(3):997-1004. http://dx.doi.org/10.1378/chest.125.3.997
27. Jones PW, Quirk FH, Baveystock CM, Littlejohns P. A selfcomplete measure of health status for chronic airflow limitation. The St. George's Respiratory Questionnaire. Am Rev Respir Dis 1992;145(6):1321-7. http://dx.doi.org/10.1164/ajrccm/145.6.1321

28. Cohen S, Kamarck T, Mermelstein R. A global measure of perceived stress. J Health Soc Behav. 1983;24(4):385-96. http://dx.doi. org/10.2307/2136404

29. Cox CE, Donohue JF, Brown CD, Kataria YP, Judson MA. The Sarcoidosis Health Questionnaire: a new measure of health-related quality of life. Am J Respir Crit Care Med. 2003;168(3):323-9. http:// dx.doi.org/10.1164/rccm.200211-13430C

30. Macintyre N, Crapo RO, Viegi G, Johnson DC, van der Grinten CP, Brusasco V, et al. Standardisation of the single-breath determination of carbon monoxide uptake in the lung. Eur Respir J. 2005;26(4):72035. http://dx.doi.org/10.1183/09031936.05.00034905

31. Quanjer PH, Tammeling GJ, Cotes JE, Pedersen OF, Peslin R Yernault JC. Lung volumes and forced expiratory flows. Official statement of European Respiratory Society. Eur Respir J. 1993:6 Suppl 16:5-40. http://dx.doi.org/10.1183/09041950.005s1693

32. Miller MR, Hankinson J, Brusasco V , Burgos F, Casaburi R, Coates A et al. Standardisation of spirometry. Eur Respir J. 2005;26(2):319-38. http://dx.doi.org/10.1183/09031936.05.00034805

33. Judson MA, Baughman RP, Thompson BW, Teirstein AS, Terrin ML, Rossman MD, et al. Two year prognosis of sarcoidosis: the ACCESS experience. Sarcoidosis Vasc Diffuse Lung Dis. 2003;20(3):204-11.

34. Baughman RP, Teirstein AS, Judson MA, Rossman MD, Yeager $\mathrm{H}$ Jr, Bresnitz EA, et al. Clinical characteristics of patients in a case control study of sarcoidosis. Am J Respir Crit Care Med. 2001;164(10 Pt 1):1885-9. http://dx.doi.org/10.1164/airccm.164.10.2104046

35. Bourbonnais JM, Samavati L. Effect of gender on health related quality of life in Sarcoidosis. Sarcoidosis Vasc Diffuse Lung Dis. 2010;27(2):96-102.

36. Iannuzzi MC, Rybicki BA, Teirstein AS. Sarcoidosis. N Engl J Med 2007;357(21):2153-65. http://dx.doi.org/10.1056/NEJMra071714 